\title{
Ideal and actual involvement of community pharmacists in health promotion and prevention: a cross-sectional study in Quebec, Canada
}

\author{
Marie-Claude Laliberté ${ }^{1,2}$, Sylvie Perreault ${ }^{1,3}$, Nicole Damestoy ${ }^{4,5,6}$ and Lyne Lalonde ${ }^{1,2,7^{*}}$
}

\begin{abstract}
Background: An increased interest is observed in broadening community pharmacists' role in public health. To date, little information has been gathered in Canada on community pharmacists' perceptions of their role in health promotion and prevention; however, such data are essential to the development of public-health programs in community pharmacy. A cross-sectional study was therefore conducted to explore the perceptions of community pharmacists in urban and semi-urban areas regarding their ideal and actual levels of involvement in providing health-promotion and prevention services and the barriers to such involvement.

Methods: Using a five-step modified Dillman's tailored design method, a questionnaire with 28 multiple-choice or open-ended questions (11 pages plus a cover letter) was mailed to a random sample of 1,250 pharmacists out of 1,887 community pharmacists practicing in Montreal (Quebec, Canada) and surrounding areas. It included questions on pharmacists' ideal level of involvement in providing health-promotion and preventive services; which services were actually offered in their pharmacy, the employees involved, the frequency, and duration of the services; the barriers to the provision of these services in community pharmacy; their opinion regarding the most appropriate health professionals to provide them; and the characteristics of pharmacists, pharmacies and their clientele.

Results: In all, 571 out of 1,234 (46.3\%) eligible community pharmacists completed and returned the questionnaire. Most believed they should be very involved in health promotion and prevention, particularly in smoking cessation (84.3\%); screening for hypertension (81.8\%), diabetes (76.0\%) and dyslipidemia (56.9\%); and sexual health (61.7\% to 89.1\%); however, fewer respondents reported actually being very involved in providing such services (5.7\% [lifestyle, including smoking cessation], 44.5\%, 34.8\%, 6.5\% and 19.3\%, respectively). The main barriers to the provision of these services in current practice were lack of: time (86.1\%), coordination with other health care professionals (61.1\%), staff or resources (57.2\%), financial compensation (50.8\%), and clinical tools (45.5\%).

Conclusions: Although community pharmacists think they should play a significant role in health promotion and prevention, they recognize a wide gap between their ideal and actual levels of involvement. The efficient integration of primary-care pharmacists and pharmacies into public health cannot be envisioned without addressing important organizational barriers.
\end{abstract}

Keywords: Community pharmacists, Cross-sectional study, Health promotion, Prevention, Public health

\footnotetext{
* Correspondence: lyne.lalonde@umontreal.ca

${ }^{1}$ Faculty of Pharmacy, Université de Montréal, C.P. 6128, Succ. Centre-ville,

Montreal, Quebec H3C 3J7, Canada

Full list of author information is available at the end of the article
} 


\section{Background}

Recently, there has been an increased interest in broadening community pharmacists' functions toward playing a greater role in public health [1]. Community pharmacies are often considered an ideal site for credible counseling for a large segment of the population because pharmacists are accessible, have frequent contact with the public, have extended opening hours, and are widely distributed geographically [1-3]. Given the increasing stresses on the health care system due to an aging population and the consequent rise in the prevalence and incidence of chronic diseases, the shift toward a wider public-health role for pharmacists should be accentuated.

Health-promotion and preventive services refer to public health services, which relate to the improvement of the general health of the population through interventions aiming at promoting health and wellbeing (e.g. nutrition, physical activity), preventing diseases (e.g. smoking cessation, immunization, travel health), identifying ill individuals (e.g. screening and case finding) and maintaining health of those with chronic conditions (e.g. diabetes, hypertension) $[4,5]$. Public health interventions act on factors influencing the health of the population as a whole or subgroups of this population rather than separate individuals, and generally take place before the onset of health problems [4]. Throughout this paper, clinical services such as medication reviews were not considered as health-promotion or preventive services since they target specific individuals.

Studies from many countries have demonstrated the benefits of pharmacy services on a wide range of important public-health issues [5]: notably in smoking cessation [6,7], diabetes [8,9], hypertension [9,10], dyslipidemia [9], contraception [11], osteoporosis [12-14], and immunization $[15,16]$. A recent Cochrane review confirmed the importance of the pharmacist's role in therapeutic management and patient counseling [17]. The broader involvement of community pharmacists is thus deemed a valuable option in addressing several public-health issues. In some countries, such as the United Kingdom, pharmacists are integrated into public-health programs [18]. In contrast, Quebec's public-health program does not stress the role of pharmacists as primary-care providers in this area [4].

To date, little information has been gathered in Canada on community pharmacists' perceptions of their role in health promotion and prevention. However, such data are essential to the development of public-health programs in community pharmacy. In this study, we documented the perceptions of community pharmacists in urban and semi-urban areas regarding their ideal and actual levels of involvement in the provision of healthpromotion and preventive services, as well as the barriers that limit their involvement.

\section{Results}

Of the 1,250 pharmacists selected, eight did not work in community pharmacy. Twelve questionnaires were returned undelivered because the address was wrong. Following the first questionnaire mailing, we were informed that one pharmacist had retired, one was on maternity leave, and one declined (verbally) to take part. Ultimately, 577 completed questionnaires were returned. However, six were returned by non-eligible pharmacists (four did not work in community pharmacy, and two were not working in a traditional community pharmacy), for a total of 571 questionnaires returned out of 1,234 eligible pharmacists (response rate: $46.3 \%$ ). More specifically, 249 questionnaires $(43.6 \%)$ were received after the first questionnaire mailing, 114 (20.0\%) after the postcard mailing, 149 (26.1\%) after the second questionnaire mailing, and 59 (10.3\%) after the third questionnaire mailing. The response rates for individual questions ranged from $87 \%$ to $100 \%$, and $99 \%$ of questions had a response rate over $90 \%$.

As reported in Table 1, the respondents were in majority women $(63.2 \%)$, were staff pharmacists $(65.3 \%)$, and reported having completed a mean 31 hours of continuing education during the past year. Their pharmacies were associated with a chain or a corporate banner $(80.4 \%)$ and/ or adjacent to a medical clinic (28.7\%). The most prevalent clienteles were elderly patients and families of average to high socio-economic status. Furthermore, 53.5\% of pharmacists reported that a nurse was present in the pharmacy for a mean 47 hours per month. Nutritionists (69 pharmacists) and naturopaths (11 pharmacists) were among other common health professionals employed in the pharmacy. Based on information from the Ordre des pharmaciens $d u$ Québec (OPQ), our respondents were similar to community pharmacists working in Quebec in terms of sex (62.4\% women in OPQ) and pharmacist status (63.9\% staff pharmacists in OPQ).

As Table 2 shows, most respondents believed they should be either "very involved" or "involved" in providing all health-promotion and preventive services. The majority reported they should ideally be "very involved" in smoking cessation (84.3\%); screening for hypertension (81.8\%), diabetes $(76.0 \%)$ and dyslipidemia (56.9\%); and sexual health (61.7\% to $89.1 \%$ ). Most considered they should be "involved" in providing information and counseling about physical activity (71.1\%), healthy eating (68.8\%), weight management (63.4\%), and alcohol consumption (63.8\%). In contrast, $54.3 \%$ and $28.5 \%$ of pharmacists, respectively, considered they should have "little involvement" or "no involvement at all" in counseling on dental health and screening for suicide risk. The proportion of respondents who reported their community pharmacy as being actually "very involved" in each service was 5.7\% for lifestylerelated activities, $44.5 \%$ for screening for hypertension, $34.8 \%$ for screening for diabetes, $6.5 \%$ for screening for 
Table 1 Characteristics of pharmacists and pharmacies

Characteristics

Characteristics of pharmacists

Sex, n (\%)

Men

Women

Practice region, n (\%)

Montreal

Laval

Laurentides

Lanaudière

Montérégie

Estrie

Outaouais

Years since graduation, $\mathrm{n}(\%)$

$\leq 10$ years

11-20 years

21-30 years

$\geq 31$ years

Pharmacist status, n (\%)

Owner pharmacist-single owner

Owner pharmacist-owner partner

Staff pharmacist

Replacement pharmacist

Staff and relief pharmacist

Hours worked per week, mean (SD ${ }^{a}$ )

Hours of continuing education during past year, mean (SD)

Private consultations in pharmacy privacy area per week, mean (SD)

\section{Characteristics of pharmacies}

Type of pharmacy, n (\%)

Pharmacy adjacent to a medical clinic

Pharmacy associated with a chain or corporate banner

$456(80.4)$

Independent pharmacy

$16(2.8)$

39 (6.9)

Pharmacy associated with a supermarket or superstore

$21(3.7)$

Pharmacy in a retirement home

$147(25.9)$

$<250$ prescriptions

$197(34.7)$

250 to 500 prescriptions

$224(39.4)$

Characteristics of most prevalent patients at the pharmacy, $\mathrm{n}(\%)^{\mathrm{b}}$

Adults (18-49 years)

$44(8.1)$

Older adults (50-65 years)

$33(6.1)$

Elderly patients (> 65 years)

$347(63.9)$

Young families

$73(13.4)$

Families

$159(29.3)$

All ages (various)

57 (10.5)

86 (15.8)

Other $^{c}$

$143(26.3)$

Low to average socio-economic status

$273(50.3)$

Average to high socio-economic status

$43(7.9)$

High socio-economic status

Availability of other health professionals in the pharmacy, $n(\%)^{b}$

Nurse

$289(53.5)$

Nutritionist 
Table 1 Characteristics of pharmacists and pharmacies (Continued)

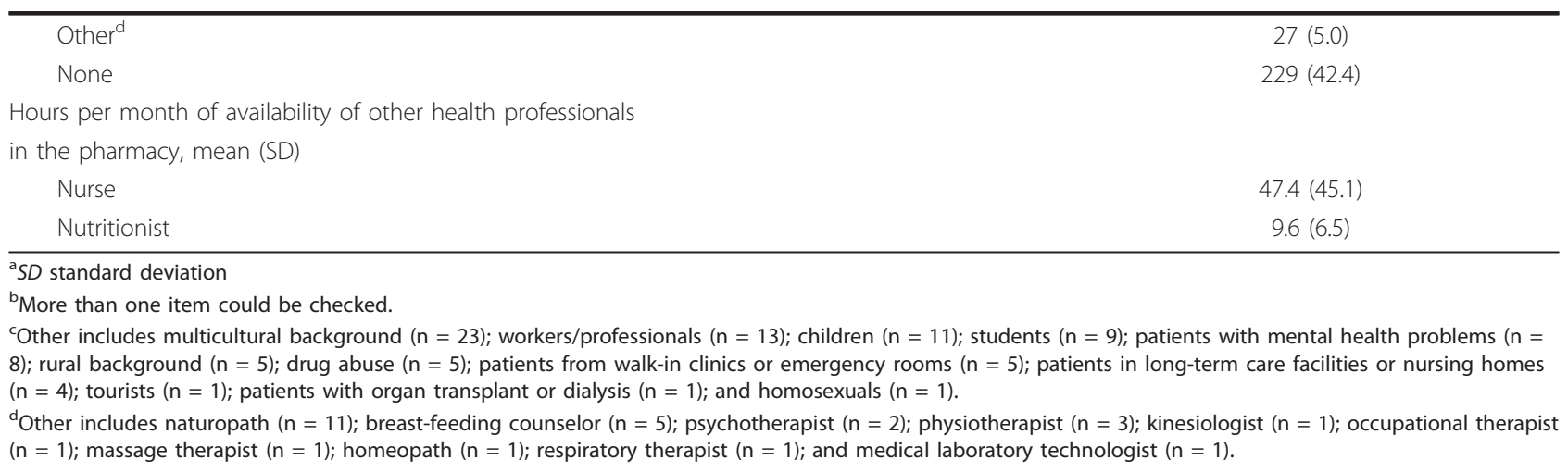

dyslipidemia and 19.3\% for sexual health. Most respondents reported their pharmacy as being either "involved" or "little involved" in lifestyle-related activities (84.5\%), screening for dyslipidemia (57.8\%), sexual health (74.5\%) and infectious diseases and immunization (72.4\%). Most appropriate primary-care providers for preventive counseling or screening were primary-care physicians, community pharmacists and nurses. They also deemed kinesiologists, nutritionists and physiotherapists well placed to offer lifestyle-related services.

As Table 3 shows, the majority of respondents identified the pharmacist as the main provider of health-promotion and preventive services in their pharmacy, though nurses and technical assistants were also frequently cited. Most pharmacists reported that preventive services are given a "few times per week" or a "few times per month" regarding: lifestyle (69.5\%), screening for hypertension (96.6\%), screening for diabetes (86.2\%), and counseling on sexual health (81.5\%). Activities related to infectious diseases and immunization were reported for the most part to take place a "few times per month" or a "few times per year" (61.8\%); 36.8\% of respondents indicated that screening for dyslipidemia never occurred. Consultations were reported to last 10 minutes or less by most pharmacists. When cases are detected during screening, most pharmacists said the report is given to the patient only (67.4\% for hypertension, $35.7 \%$ for dyslipidemia and $67.9 \%$ for diabetes); smaller percentages said the report is given to both the patient and the primary-care physician $(33.5 \%$ for hypertension, $18.6 \%$ for dyslipidemia and $31.4 \%$ for diabetes).

Pharmacists were also asked to report the actual specific activities provided in their pharmacy. As indicated in Table 4, the majority reported distributing written information, providing personalized counseling when dispensing medications and referring patients to external resources. A large proportion of respondents said personalized follow-up for smoking cessation (44.5\%), hypertension $(53.7 \%)$, diabetes $(45.0 \%)$, and emergency oral contraception (40.7\%) were provided. Many pharmacists provided no prevention activities regarding dental health
(29.3\%), suicide risk (27.6\%) or needle exchange (35.2\%). Many tasks were performed by a nurse or a nutritionist; 31 pharmacists thus reported that immunization was conducted by a nurse. Several pharmacists reported having a collective prescription for smoking cessation (39 pharmacists). Collective prescriptions enable authorized professionals, usually pharmacists or nurses, to perform certain tasks (for example, requesting laboratory tests and adjusting medication dosage) without first having to obtain an individual prescription from a physician [19].

As reported in Figure 1 the main barriers to providing health-promotion and preventive services in their current practice were lack of time (86.1\%), lack of coordination with other health care professionals (61.1\%), lack of staff or resources (57.2\%), lack of financial compensation (50.8\%), and lack of clinical tools (45.5\%). Six pharmacists also indicated that their limited prescription rights and the lack of collective prescriptions further hampered their involvement in prevention.

${ }^{a}$ More than one item could be checked.

${ }^{\mathrm{b}}$ Other includes limited prescription rights for pharmacists and lack of collective prescriptions $(n=6)$; patients are often in a rush and don't have time for prevention activities $(\mathrm{n}=3)$; patients are not "open" to change $(\mathrm{n}=$ 3 ); too many technical tasks performed by the pharmacist $(\mathrm{n}=2)$; patients do not think of pharmacists for prevention activities $(\mathrm{n}=2)$; no standardized practice model $(\mathrm{n}=$ 2); lack of access to lab-test results and other patient information $(n=2)$; pharmacists are overworked $(n=2)$; nurses already perform some of these activities $(n=2)$; lack of a closed office at the pharmacy $(n=1)$; low uptake of pharmacist's suggestions by physicians $(n=1)$; home visits are expensive $(n=1)$; pharmacy owners not often present at the pharmacy $(\mathrm{n}=1)$; pharmacist shortage $(\mathrm{n}=$ 1); patients don't like to be "criticized" about their lifestyle $(n=1)$; relief pharmacists don't know the pharmacy's patients very well $(n=1)$; the logistics of implementation in general $(n=1)$; most of the pharmacy's patients are not regular patients $(n=1)$; lack of patient knowledge about the benefits of prevention $(n=1)$; lack of tools for patients 
Table 2 Ideal and actual levels of involvement of community pharmacists and most appropriate primary-care providers for these services

\begin{tabular}{|c|c|c|c|c|}
\hline Services & Very involved $\mathrm{n}(\%)$ & Involved n (\%) & $\begin{array}{l}\text { Little involved } \\
\mathrm{n}(\%)\end{array}$ & $\begin{array}{c}\text { Not at all } \\
\text { involved } n(\%)\end{array}$ \\
\hline \multicolumn{5}{|l|}{ Ideal level of involvement } \\
\hline \multicolumn{5}{|l|}{ Lifestyle } \\
\hline Smoking cessation & $478(84.3)$ & $85(15.0)$ & $4(0.7)$ & $0(0)$ \\
\hline Physical-activity promotion & $94(16.6)$ & $403(71.1)$ & $68(12.0)$ & $2(0.4)$ \\
\hline Healthy eating & $97(17.2)$ & $389(68.8)$ & $76(13.5)$ & $3(0.5)$ \\
\hline Weight management & $128(22.6)$ & $359(63.4)$ & $75(13.3)$ & $4(0.7)$ \\
\hline Alcohol consumption & $80(14.1)$ & $361(63.8)$ & $117(20.7)$ & $8(1.4)$ \\
\hline Dental health & $27(4.8)$ & $231(40.9)$ & $281(49.7)$ & $26(4.6)$ \\
\hline \multicolumn{5}{|l|}{ Screening for: } \\
\hline Hypertension & $464(81.8)$ & $96(16.9)$ & $7(1.2)$ & $0(0)$ \\
\hline Diabetes & $431(76.0)$ & $127(22.4)$ & $9(1.6)$ & $0(0)$ \\
\hline Dyslipidemia & $322(56.9)$ & $217(38.3)$ & $24(4.2)$ & $3(0.5)$ \\
\hline Risk of suicide & $138(24.4)$ & $266(47.1)$ & $148(26.2)$ & $13(2.3)$ \\
\hline \multicolumn{5}{|l|}{ Sexual health } \\
\hline $\begin{array}{l}\text { Emergency oral } \\
\text { contraception }\end{array}$ & $505(89.1)$ & $58(10.2)$ & $3(0.5)$ & $1(0.2)$ \\
\hline Contraception & $361(63.7)$ & $191(33.7)$ & $15(2.6)$ & $0(0)$ \\
\hline $\begin{array}{l}\text { Counseling with partners when initiating treatment for } \\
\text { sexually transmitted diseases }\end{array}$ & $350(61.7)$ & $194(34.2)$ & $21(3.7)$ & $2(0.4)$ \\
\hline \multicolumn{5}{|l|}{ Infectious diseases and immunization } \\
\hline Travel health & $242(42.8)$ & $276(48.8)$ & $44(7.8)$ & $4(0.7)$ \\
\hline Needle-exchange programs & $259(45.8)$ & $236(41.8)$ & $60(10.6)$ & $10(1.8)$ \\
\hline Immunization programs & $163(28.8)$ & $313(55.4)$ & $82(14.5)$ & $7(1.2)$ \\
\hline \multicolumn{5}{|l|}{ Actual level of involvement } \\
\hline Lifestyle & $32(5.7)$ & $232(41.3)$ & $243(43.2)$ & $55(9.8)$ \\
\hline Screening for hypertension & $252(44.5)$ & $267(47.2)$ & $42(7.4)$ & $5(0.9)$ \\
\hline Screening for diabetes & $198(34.7)$ & $255(44.7)$ & $100(17.5)$ & $17(3.0)$ \\
\hline Screening for dyslipidemia & $37(6.5)$ & $150(26.5)$ & $177(31.3)$ & $202(35.7)$ \\
\hline Sexual health & 109 (19.3) & $274(48.5)$ & $147(26.0)$ & $35(6.2)$ \\
\hline Infectious diseases and immunization & $48(8.6)$ & 189 (33.8) & $216(38.6)$ & $107(19.1)$ \\
\hline Most appropriate providersa & $\begin{array}{c}\text { Primary care } \\
\text { physicians n (\%) }\end{array}$ & $\begin{array}{c}\text { Community } \\
\text { pharmacists } n(\%)\end{array}$ & Nurses n (\%) & $\begin{array}{c}\text { Other or nonen } \\
\mathrm{n}(\%)\end{array}$ \\
\hline Lifestyle & $327(61.0)$ & $379(70.7)$ & $354(66.0)$ & $166(31.0) b$ \\
\hline Screening for hypertension & $399(71.6)$ & $520(93.4)$ & $429(77.0)$ & $22(4.0) c$ \\
\hline Screening for dyslipidemia & $443(83.1)$ & $328(61.5)$ & $311(58.3)$ & $22(4.2) d$ \\
\hline Screening for diabetes & $419(75.2)$ & $494(88.7)$ & $442(79.4)$ & 27 (4.9)e \\
\hline Sexual health & $427(77.6)$ & $488(88.7)$ & $416(75.6)$ & $13(2.3) f$ \\
\hline Infectious diseases and immunization & $371(70.3)$ & $313(59.3)$ & $450(85.2)$ & $17(3.2) \mathrm{g}$ \\
\hline
\end{tabular}

${ }^{a}$ More than one item could be checked.

${ }^{b}$ Other includes kinesiologists $(n=48)$; nutritionists $(n=46)$; physiotherapists $(n=28)$; personal trainers in gyms $(n=12)$; dieticians $(n=12)$; occupational therapists $(n=11)$; physical educators in schools $(n=10)$; all health professionals as multidisciplinary teams $(n=7)$; government $(n=5)$; public-health agencies $(n=4)$; technical assistants $(n=2)$; local community service centre $(C L S C)(n=2)$; community support groups $(n=2)$; technicians $(n=2)$; recreation consultants $(\mathrm{n}=1)$; and pharmacy students $(\mathrm{n}=1)$.

'Other includes technical assistants $(n=9)$; pharmacy students $(n=3)$; technicians $(n=3)$; the patient him/herself $(n=3)$; and CLSC $(n=2)$.

${ }^{d}$ Other includes nutritionists $(n=6)$; technical assistants $(n=1)$; $\operatorname{CLSC}(n=1)$; dieticians $(n=1)$; and pharmacy students ( $\left.n=1\right)$.

eOther includes technical assistants $(n=8)$; nutritionists $(n=7)$; dieticians $(n=3)$; diabetes clinic $(n=3)$; CLSC $(n=2)$; physiotherapists $(n=1)$; technicians $(n=$ $1)$; and the patient him/herself $(n=1)$.

fOther includes CLSC ( $n=5)$; schools $(n=3)$; public-health agencies $(n=1)$; and sexologists $(n=1)$.

${ }^{g}$ Other includes travel clinic $(n=5)$; CLSC $(n=4)$; and public-health agencies $(n=1)$. 
Table 3 Characteristics of health-promotion and preventive services

\begin{tabular}{|c|c|c|c|c|c|c|}
\hline & Lifestyle & $\begin{array}{l}\text { Screening for } \\
\text { hypertension }\end{array}$ & $\begin{array}{l}\text { Screening for } \\
\text { dyslipidemia }\end{array}$ & $\begin{array}{l}\text { Screening for } \\
\text { diabetes }\end{array}$ & $\begin{array}{l}\text { Sexual } \\
\text { health }\end{array}$ & $\begin{array}{l}\text { Infectious diseases and } \\
\text { immunization }\end{array}$ \\
\hline \multicolumn{7}{|c|}{ Main person(s) providing health-promotion and preventive services, $\mathrm{n}(\%)^{\mathrm{a}}$} \\
\hline Pharmacist & $\begin{array}{l}432 \\
(80.0)\end{array}$ & $497(88.0)$ & $202(38.5)$ & $462(82.2)$ & $\begin{array}{l}522 \\
(94.2)\end{array}$ & $348(65.7)$ \\
\hline Technical assistant & $32(5.9)$ & $177(31.3)$ & $17(3.2)$ & $151(26.9)$ & $13(2.3)$ & $19(3.6)$ \\
\hline Nurse & $\begin{array}{l}143 \\
(26.5)\end{array}$ & $215(38.1)$ & $197(37.6)$ & $241(42.9)$ & $58(10.5)$ & $9(1.7)$ \\
\hline Other & $23(4.3)^{\mathrm{b}}$ & $21(3.7)^{c}$ & $9(1.7)^{d}$ & $11(2.0)^{\mathrm{e}}$ & $3(0.5)^{f}$ & $2(0.4)^{9}$ \\
\hline None & $73(13.5)$ & $5(0.9)$ & $168(32.1)$ & $11(2.0)$ & $28(5.1)$ & $80(15.1)$ \\
\hline \multicolumn{7}{|c|}{ Frequency with which health-promotion and preventive services are provided, $\mathrm{n}(\%)^{\mathrm{a}}$} \\
\hline Few times per week & $\begin{array}{l}203 \\
(38.2)\end{array}$ & $465(82.6)$ & $96(18.4)$ & $301(53.8)$ & $\begin{array}{c}249 \\
(45.4)\end{array}$ & $116(22.0)$ \\
\hline Few times per month & $\begin{array}{c}166 \\
(31.3)\end{array}$ & $79(14.0)$ & $133(25.5)$ & $181(32.4)$ & $\begin{array}{c}198 \\
(36.1)\end{array}$ & $171(32.4)$ \\
\hline Few times per year & $94(17.7)$ & $21(3.7)$ & $107(20.5)$ & $77(13.8)$ & $63(11.5)$ & $155(29.4)$ \\
\hline Never & $74(13.9)$ & $6(1.1)$ & $192(36.8)$ & $9(1.6)$ & $40(7.3)$ & $89(16.9)$ \\
\hline \multicolumn{7}{|c|}{ Duration of consultations related to health promotion and prevention, $n(\%)^{a}$} \\
\hline Less than 5 minutes & $\begin{array}{c}255 \\
(48.5)\end{array}$ & $157(27.9)$ & $71(13.8)$ & $97(17.3)$ & $\begin{array}{c}128 \\
(23.4)\end{array}$ & $149(28.6)$ \\
\hline 5-10 minutes & $\begin{array}{c}153 \\
(29.1)\end{array}$ & $324(57.7)$ & $151(29.3)$ & $301(53.8)$ & $\begin{array}{c}279 \\
(50.9)\end{array}$ & $180(34.5)$ \\
\hline 11-15 minutes & $51(9.7)$ & $80(14.2)$ & $85(16.5)$ & $139(24.8)$ & $99(18.1)$ & $85(16.3)$ \\
\hline More than 15 minutes & $19(3.6)$ & $10(1.8)$ & $25(4.9)$ & $39(7.0)$ & $15(2.7)$ & $29(5.6)$ \\
\hline No consultation provided & $72(13.7)$ & $7(1.2)$ & $188(36.5)$ & $12(2.1)$ & $32(5.8)$ & $87(16.7)$ \\
\hline \multicolumn{7}{|c|}{ Type(s) of follow-up for cases detected during screening, $n(\%)^{a}$} \\
\hline Report given to patient only & $0(0)$ & $372(67.4)$ & $178(35.7)$ & $374(67.9)$ & $0(0)$ & $0(0)$ \\
\hline Report given to primary-care physician & $0(0)$ & $25(4.5)$ & $12(2.4)$ & $22(4.0)$ & $0(0)$ & $0(0)$ \\
\hline only & $0(0)$ & $185(33.5)$ & $93(18.6)$ & $173(31.4)$ & $0(0)$ & $0(0)$ \\
\hline $\begin{array}{l}\text { Report given to patient and primary- } \\
\text { care physician }\end{array}$ & $0(0)$ & $4(0.7)$ & $2(0.4)$ & $6(1.1)$ & $0(0)$ & $0(0)$ \\
\hline $\begin{array}{l}\text { Link with the Centre de santé et de } \\
\text { services sociaux Not applicable }\end{array}$ & $0(0)$ & $28(5.1)$ & $232(46.5)$ & $36(6.5)$ & $0(0)$ & $0(0)$ \\
\hline
\end{tabular}

${ }^{a}$ More than one item could be checked.

${ }^{b}$ Other includes nutritionists $(n=16)$; pharmacy students $(n=5)$; and dieticians $(n=2)$.

'Other includes blood-pressure device available at the pharmacy $(n=9)$; pharmacy students $(n=8)$; nursing students ( $n=3$ ); and over-the-counter medications salesperson $(n=1)$.

${ }^{d}$ Other includes pharmacy students $(n=6)$; nutritionist $(n=2)$; and dietician $(n=1)$.

e Other includes pharmacy students $(n=4)$; nutritionist $(n=3)$; over-the-counter medications salesperson $(n=2)$; nursing students $(n=1)$; and the patient in the presence of the pharmacist $(n=1)$.

fOther includes pharmacy students $(n=3)$.

${ }^{g}$ Other includes pharmacy students $(n=1)$ and travel clinic at the pharmacy $(n=1)$.

$(\mathrm{n}=1)$; pharmacy's patients do not need preventive activities because they are already educated about the subject $(\mathrm{n}=1)$; lack of external resources to which patients can be referred $(\mathrm{n}=1)$; lack of budget for prevention activities at the pharmacy $(\mathrm{n}=1)$; lack of competent and stable staff ( $\mathrm{n}$ $=1$ ); lack of interest by pharmacy owners $(\mathrm{n}=1)$; and the topic of prevention is very broad, so pharmacists provide counseling on a little bit of everything but about nothing in depth $(\mathrm{n}=1)$.

\section{Discussion}

Community pharmacists in Montreal (Quebec, Canada) and surrounding areas perceive their potential role in health promotion and prevention as very significant, particularly in smoking cessation, screening for hypertension, diabetes and dyslipidemia, and counseling on sexual health. However, there is a wide gap between their ideal and actual levels of involvement. Most pharmacists believe they should be very involved in screening for hypertension (81.8\%), diabetes (76.0\%) and dyslipidemia (56.9\%); in fact, though, only a minority is very involved $(44.5 \%, 34.8 \%$ and $6.5 \%$, respectively). Health-promotion and preventive services in pharmacy are provided largely by pharmacists and, to a lesser extent, by nurses and technical assistants. In fact, more than half of surveyed pharmacists reported that a nurse was present in their pharmacy. The services 
consist mainly of distributing written information, providing counseling when dispensing medications and referring patients to external resources. When offered, such services are provided relatively often and usually take 10 minutes or less. There are several barriers that limit pharmacists' involvement in health promotion and prevention, including lack of time, lack of coordination with other health care professionals, lack of staff or resources, lack of financial compensation, and lack of clinical tools.

Similarly to the present study, the results of a crosssectional mail survey of community pharmacists in British Columbia published in 1994 showed that pharmacists are mostly involved in activities directly related to the dispensing or selling of medications and have less intense involvement in health education and disease prevention [2]. A 1996 cross-sectional mail survey of community pharmacists practicing in the province of Quebec found that, although only few pharmacists reported routinely performing prevention activities, over $90 \%$ believed that integrating prevention into their practices was important [1]. Similarly, a Web-based survey of pharmacists across Canada reported that, although pharmacists currently spend most of their time on dispensing duties, over $60 \%$ believed it was time to assume new responsibilities, and more than $70 \%$ wanted to expand their roles in various fields including public health outreach (e.g. working with communities and patients to focus on health promotion, disease prevention and chronic disease management) within five years [20]. Finally, a recent systematic review on the beliefs and attitudes of pharmacists regarding pharmaceutical public health showed that, although most view public-health services as important and part of their role, various organizational barriers limit their involvement [21]. These results confirm the profession's widespread acceptance of community pharmacists' changing role from traditional dispensing duties to greater involvement in health promotion and prevention and its understanding of the importance of providing these services.

Evidently, pharmacists and the population at large would welcome greater involvement of community pharmacies in health-promotion and preventive services [21,22]. Our results suggest that the development of future publichealth programs in community pharmacy should focus on the continuity of care, maximizing the expertise of other health care professionals who may be present in the pharmacy, and overcoming organizational barriers. Such programs need to be well integrated within the primary-care system through effective communication and collaboration with other health care providers, and they should be supported by clinical tools, such as collective prescriptions, to optimize the contribution of pharmacists.

In a study evaluating the impact of a community pharmacy-based smoking cessation program in Northern Ireland, the involvement of pharmacies was especially low: only $19 \%$ of recruited pharmacies enrolled the required number of patients to participate in the study [7]. This is in line with the results of the present study, suggesting that although pharmacists may envision an ideal level of involvement in health-promotion and preventive services, this vision is often not translated into their actual practice. In formal clinical trials where the level of involvement of pharmacists in specific public-health activities may be considered as ideal, beneficial impacts have been identified, namely in the area of smoking cessation [6,7], hypertension $[9,10]$, dyslipidemia [9], diabetes $[8,9]$, and sexual health [11]. Integrating primary-care pharmacists and pharmacies into public-health programs should be considered a valuable option for optimizing population health. It is therefore crucial to better understand the barriers and facilitators of greater involvement of pharmacists in public health activities.

Similarly again to our results, studies have identified key barriers to the involvement of community pharmacists in health promotion and prevention. They include the lack of time, insufficient human resources, difficult access to patients' physicians, lack of skills and/or instrumentation, lack of compensation for prevention acts, and lack of space [1,23-25]. Other factors limiting the provision of such activities in current practice that were found in the literature but did not stand out in our study include the general public's lack of awareness of pharmacy's role in health promotion and prevention, lack of access to the full patient record, confidentiality concerns, and defensive or uncooperative patients [23-26]. It is therefore to be expected that overcoming these barriers will require reorganizing not only community-pharmacy practice but also the health care system in order to better integrate pharmacists into the provision of preventive services. This reorganization will doubtless require agreement, commitment and engagement by all pharmacy stakeholders in addition to financial investments.

Two studies have identified facilitators of practice change in community pharmacy $[27,28]$. These factors included government policy; remuneration for service delivery; communication and teamwork; leadership; task delegation; external support or assistance; reorganization of the structure and function of the pharmacy; professional satisfaction or competitiveness; communication and collaboration with physicians; and patient expectations regarding the services to be offered. Future public-health programs in community pharmacy will also need to consider these factors in order to facilitate practice change.

This study has some limitations. No data were collected regarding non-respondents; it is therefore possible that the pharmacists who returned the completed questionnaire are more motivated or interested than the non-respondents are and that involvement in health promotion and prevention may thus have been overestimated. A social-desirability 
Table 4 Specific activities conducted in health-promotion and preventive services in community pharmacies ${ }^{a}$

\begin{tabular}{|c|c|c|c|c|c|c|c|}
\hline Services & $\begin{array}{l}\text { Distribution of } \\
\text { written } \\
\text { information } \\
n(\%)\end{array}$ & $\begin{array}{c}\text { Personalized } \\
\text { counseling } \\
\text { when } \\
\text { Dispensing } \\
\text { medications } \\
\text { n (\%) }\end{array}$ & $\begin{array}{l}\text { Screening }^{b} \\
\text { n (\%) }\end{array}$ & $\begin{array}{l}\text { Referral to } \\
\text { external } \\
\text { resources } \\
\mathrm{n}(\%)\end{array}$ & $\begin{array}{c}\text { Personalized follow- } \\
\text { up or private } \\
\text { consultation } \\
\text { n (\%) }\end{array}$ & $\begin{array}{l}\text { Other } \\
\text { n (\%) }\end{array}$ & $\begin{array}{c}\text { None } \\
n \\
(\%)\end{array}$ \\
\hline \multicolumn{8}{|l|}{ Lifestyle } \\
\hline Smoking cessation & $386(68.2)$ & $509(89.9)$ & $193(34.1)$ & $283(50.0)$ & $252(44.5)$ & $\begin{array}{c}44 \\
(7.8)^{c}\end{array}$ & $0(0)$ \\
\hline Physical-activity promotion & $154(27.8)$ & $349(63.0)$ & $20(3.6)$ & $169(30.5)$ & $23(4.2)$ & $9 \underset{d}{(1.6)}$ & $\begin{array}{c}51 \\
(9.2)\end{array}$ \\
\hline Healthy eating & $304(54.0)$ & $355(63.1)$ & $43(7.6)$ & $297(52.8)$ & $30(5.3)$ & $\begin{array}{c}29 \\
(5.2)^{\mathrm{e}}\end{array}$ & $\begin{array}{c}16 \\
(2.8)\end{array}$ \\
\hline Weight management & $150(27.3)$ & $277(50.4)$ & $42(7.6)$ & $257(46.7)$ & $23(4.2)$ & $\begin{array}{c}25 \\
(4.5)^{f}\end{array}$ & $\begin{array}{c}72 \\
(13.1)\end{array}$ \\
\hline Alcohol consumption & $75(13.6)$ & $309(56.1)$ & $32(5.8)$ & $155(28.1)$ & $16(2.9)$ & $3 \underset{g}{(0.5)}$ & $\begin{array}{c}116 \\
(21.1)\end{array}$ \\
\hline Dental health & $47(8.7)$ & $180(33.1)$ & $13(2.4)$ & $262(48.3)$ & $7(1.3)$ & $4 \underset{h}{(0.7)}$ & $\begin{array}{c}159 \\
(29.3)\end{array}$ \\
\hline \multicolumn{8}{|l|}{ Screening for: } \\
\hline Hypertension & $344(60.8)$ & $480(84.8)$ & $417(73.7)$ & $186(32.9)$ & $304(53.7)$ & $\begin{array}{c}35 \\
(6.2)^{i}\end{array}$ & $\begin{array}{c}6 \\
(1.1)\end{array}$ \\
\hline Diabetes & $364(64.5)$ & $489(86.7)$ & $351(62.2)$ & $246(43.6)$ & $254(45.0)$ & $\begin{array}{c}33 \\
(5.9)^{j}\end{array}$ & $\begin{array}{c}8 \\
(1.4)\end{array}$ \\
\hline Dyslipidemia & $319(57.1)$ & $471(84.3)$ & $140(25.0)$ & $161(28.8)$ & $132(23.6)$ & $\begin{array}{c}22 \\
(3.9)^{k}\end{array}$ & $\begin{array}{c}21 \\
(3.8)\end{array}$ \\
\hline Risk of suicide & $81(15.1)$ & $190(35.4)$ & $44(8.2)$ & $239(44.6)$ & $67(12.5)$ & $2(0.4)$ & $\begin{array}{c}148 \\
(27.6)\end{array}$ \\
\hline \multicolumn{8}{|l|}{ Sexual health } \\
\hline Emergency oral contraception & $227(40.2)$ & $497(88.0)$ & $122(21.6)$ & $137(24.2)$ & $230(40.7)$ & $\begin{array}{c}26 \\
(4.6)^{m}\end{array}$ & $\begin{array}{c}10 \\
(1.8)\end{array}$ \\
\hline Contraception & $214(38.1)$ & $510(90.7)$ & $58(10.3)$ & $220(39.1)$ & $105(18.7)$ & $2 \underset{n}{(0.4)}$ & $\begin{array}{c}11 \\
(2.0)\end{array}$ \\
\hline $\begin{array}{l}\text { Counseling with partners when } \\
\text { initiating treatment for sexually } \\
\text { transmitted diseases }\end{array}$ & $111(19.8)$ & $488(87.0)$ & $36(6.4)$ & $166(29.6)$ & $51(9.1)$ & $0(0)$ & $\begin{array}{c}30 \\
(5.3)\end{array}$ \\
\hline \multicolumn{8}{|l|}{ Infectious diseases and immunization } \\
\hline Travel health & $241(43.0)$ & $412(73.4)$ & $78(13.9)$ & $319(56.9)$ & $58(10.3)$ & $\begin{array}{c}40 \\
(7.1)^{\circ}\end{array}$ & $\begin{array}{c}28 \\
(5.0)\end{array}$ \\
\hline Needle exchange programs & $91(16.9)$ & $163(30.4)$ & $34(6.3)$ & $117(21.8)$ & $14(2.6)$ & $\begin{array}{c}67 \\
(12.5) \\
p\end{array}$ & $\begin{array}{c}189 \\
(35.2)\end{array}$ \\
\hline Immunization programs & 207 (37.3) & $267(48.1)$ & $50(9.0)$ & $274(49.4)$ & $45(8.1)$ & $\begin{array}{c}45 \\
(8.1)^{q}\end{array}$ & $\begin{array}{c}82 \\
(14.8)\end{array}$ \\
\hline
\end{tabular}

${ }^{a}$ More than one item could be checked.

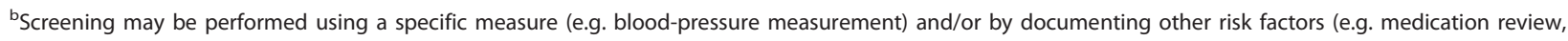
interview with the patient).

'Other includes collective prescription $(n=39)$; health clinic at the pharmacy $(n=1)$; service offered by a nurse at the pharmacy $(n=1)$; oral presentations $(n=$ $1)$; referral to the "iQuitnow" organization ( $n=1)$; and answers to patients' questions $(n=1)$.

dOther includes answers to patients' questions $(n=5)$; service offered by a nurse at the pharmacy $(n=2)$; oral presentations $(n=1)$; and referral to a website $(n$ $=1)$.

eOther includes service offered by a nutritionist at the pharmacy $(n=13)$; counseling by a nurse at the pharmacy ( $n=7)$; answers to patients' questions ( $n=4)$; health clinic at the pharmacy $(n=3)$; referral to a website $(n=1)$; and distribution of Canada's Food Guide $(n=1)$.

fOther includes service by a nurse at the pharmacy $(n=10)$; service by a nutritionist at the pharmacy $(n=7)$; answers to patients' questions ( $n=3)$; distribution of Canada's Food Guide $(n=1)$; referral to a website $(n=1)$; body-mass index measurement $(n=1)$; counseling on over-the-counter medications ( $n=1)$; and health clinic at the pharmacy $(n=1)$.

${ }^{g}$ Other includes answers to patients' questions $(n=2)$ and referral to a website $(n=1)$.

hOther includes counseling on over-the-counter products $(n=2)$ and answers to patients' questions $(n=2)$.

'Other includes service by a nurse at the pharmacy $(n=16)$; blood-pressure measurement at the pharmacy $(n=8)$; ambulatory blood pressure monitoring ( $n=$ 6); health clinic at the pharmacy $(n=3)$; "Tension Attention" program $(n=1)$; and follow-up with the physician $(n=1)$. 


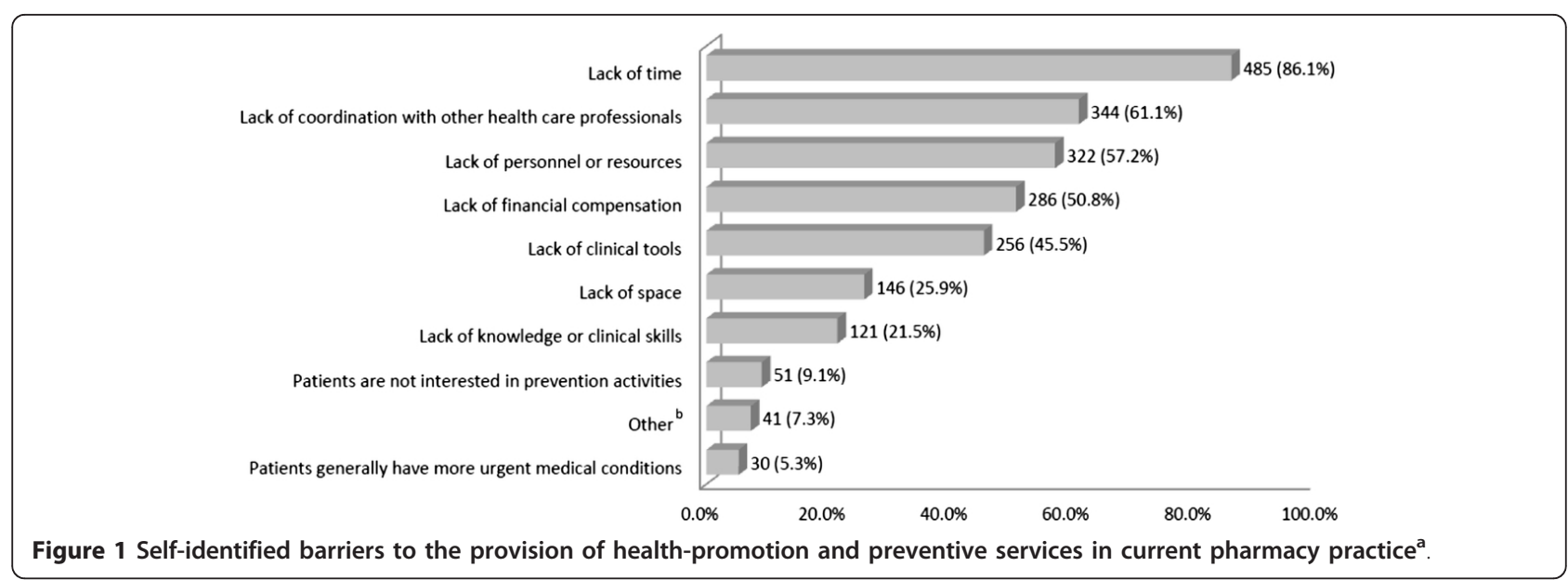

bias may also have contributed to overestimate the ideal and actual prevention practices. Finally, the length of the questionnaire may have contributed to reduce the response rate. Nonetheless, despite random sampling and the absence of any telephone contact, the response rate was relatively high. Moreover, comparison with statistics compiled by the OPQ on gender and pharmacist status showed that our sample was representative of community pharmacists working in Quebec.

\section{Conclusions}

In conclusion, community pharmacists strongly believe they should play a significant role in health promotion and prevention. However, given the many organizational barriers limiting their current public health activities, a wide gap exists between their ideal and actual levels of involvement.

\section{Methods}

\section{Study design}

In this cross-sectional study, a self-administered questionnaire was mailed to a random sample of 1,250 community pharmacists practicing in Montreal and surrounding areas from December 8, 2010, to February 23, 2011. The study was approved by the Research Ethics Committee of the Centre de santé et de services sociaux de Laval (Quebec, Canada). As an incentive, each respondent was eligible for a random draw of one of 10 prizes of $\$ 500$.

\section{Sampling procedures}

Using the OPQ's 2010 listing, which includes work-place or home addresses, 1,887 community pharmacists were identified in Montreal, Laval, Laurentides, Lanaudière, Montérégie, Estrie, and Outaouais. Pharmacists working in acute- and chronic-care hospitals or institutions are not included in the list. A random sample of 1,250 pharmacists weighted by the number of pharmacists in each region was constituted: Montreal ( $\mathrm{n}=481$ or $38.5 \%)$,
Laval $(\mathrm{n}=119,9.5 \%)$, Laurentides $(\mathrm{n}=125,10.0 \%)$, Lanaudière $(\mathrm{n}=103,8.2 \%)$, Montérégie $(\mathrm{n}=313,25.0 \%)$, Estrie $(n=64,5.1 \%)$, and Outaouais $(n=45,3.6 \%)$.

\section{Mailings}

A modified version of Dillman's tailored design method [29] was used to send the questionnaire to community pharmacists. The procedure comprised: 1) a personalized letter of invitation describing the study; 2) a first mailing of the questionnaire one week after the invitation; 3 ) a reminder postcard sent to non-respondents two weeks after the first questionnaire mailing; 4 ) a second mailing of the questionnaire to non-respondents two weeks after the postcard; and 5) a third mailing of the questionnaire to non-respondents three weeks after the second questionnaire mailing. Questionnaire mailings included a prepaid, preaddressed return envelope.

\section{Questionnaire}

The questionnaire was written in French and is available online [30]. The questionnaire was not translated in English because in Quebec, all pharmacy programs including bridging programs for pharmacists from outside of Quebec are offered in French; all pharmacists in Quebec must therefore read, write and speak French. It consisted of 28 questions (in 11 pages plus a cover letter) and took around 25 minutes to complete. These questions were inspired by, but not restricted to, two previous questionnaires regarding the role of community pharmacists in health education and disease prevention [1,26], and questions were reviewed for relevance by all authors. The questionnaire was pretested for comprehension, language, relevance, and acceptability with a convenience sample of five volunteer community pharmacists who were not considered for participation in the study.

The first set of questions documented community pharmacists' ideal level of involvement in providing health-promotion and preventive services. Pharmacists 
were then asked to indicate which services were actually offered in their pharmacy, the employees involved, and the frequency and duration of the services. Finally, we documented their perceptions of the barriers to providing health-promotion and preventive services in community pharmacy and their opinion regarding the most appropriate health professionals to provide them. We also documented the characteristics of pharmacists, pharmacies and their clientele.

Pharmacists working in more than one community pharmacy were asked to refer to the one in which they worked most of the time. Respondents' characteristics were compared with the characteristics reported for Quebec pharmacists in the OPQ's annual report [31].

\section{Statistical analyses}

The characteristics of pharmacists and their community pharmacies were described using means (and standard deviations) for continuous variables and proportions for discrete variables. For the questions on community pharmacists' role in health promotion and prevention and on the barriers to the provision of such services, the proportions of respondents selecting each possible answer were computed. With a sample of 571 respondents, the margin of error is estimated to be $\pm 4.1 \% 19$ times out of 20 , assuming a probability of $50 \%$. Analyses were performed using SPSS software, version 19.0 (SPSS Inc., Chicago, IL).

\section{Financial disclosure}

Réseau québécois de recherche sur l'usage des médicaments (RQRUM) and Agence de la santé et des services sociaux de Laval

\section{Abbreviations \\ CLSC: Local community service centre; OPQ: Ordre des pharmaciens du Québec}

\section{Acknowledgements}

$\mathrm{MCL}$ is supported by a doctoral research award from the Canadian Institutes of Health Research (CIHR) in partnership with Osteoporosis Canada. LL and SP are research scholars who receive financial support from the Fonds de recherche du Québec - Santé. We thank all participants who responded to the questionnaire.

\section{Author details}

${ }^{1}$ Faculty of Pharmacy, Université de Montréal, C.P. 6128, Succ. Centre-ville, Montreal, Quebec H3C 3J7, Canada. Équipe de recherche en soins de première ligne, Centre de santé et de services sociaux de Laval, 1755 RenéLaennec Blvd, room D-S080, Laval, Quebec H7M 3L9, Canada. ${ }^{3}$ Sanofi Aventis Endowment Chair in Drug Utilization, Faculty of Pharmacy, Université de Montréal, C.P. 6128, Succ. Centre-ville, Montreal, Quebec H3C 3J7, Canada. ${ }^{4}$ Direction Prévention-Promotion, Centre de santé et de services sociaux de Laval, 800 Chomedey Blvd, Tour A, Laval, Quebec H7V 3Y4, Canada. ${ }^{5}$ Direction de santé publique, Agence de la santé et des services sociaux de Laval, 800 Chomedey Blvd, Tour A, Laval, Quebec H7V 3Y4, Canada. ${ }^{6}$ Faculty of Medicine, Université de Montréal, C.P. 6128, Succ. Centre-ville, Montreal, Quebec H3C 3J7, Canada. ${ }^{7}$ Sanofi Aventis Endowment Chair in Ambulatory Pharmaceutical Care, Faculty of Pharmacy, Université de Montréal, C.P. 8128, Succ. Centre-ville, Montreal, Quebec H3C 3J7, Canada.

\section{Authors' contributions}

MCL participated in the design of the study, performed the data collection, carried out the statistical analyses, interpreted the data and wrote the article as first author. SP, ND and LL all contributed to the design of the study, interpreted the data, revised critically the manuscript and approved the final version.

\section{Competing interests}

$M C L, S P$ and ND declare no competing interests. LL has unrestricted educational and research funding from Amgen Canada, AstraZeneca Canada Inc., Janssen-Ortho Inc., Merck Frosst Canada Ltd., Pfizer Canada Inc., Purdue Pharma Canada, and Leo Pharma.

Received: 21 December 2011 Accepted: 15 March 2012

Published: 15 March 2012

\section{References}

1. O'Loughlin J, Masson P, Dery V, Fagnan D: The role of community pharmacists in health education and disease prevention: a survey of their interests and needs in relation to cardiovascular disease. Prev Med 1999, 28:324-331.

2. Paluck EC, Stratton TP, Eni GO: Community pharmacists' participation in health education and disease prevention activities. Can J Public Health 1994, 85:389-392.

3. Chandra A, Malcolm N, Fetters M: Practicing health promotion through pharmacy counseling activities. Health Promot Pract 2003, 4:64-71.

4. Direction générale de la santé publique du ministère de la Santé et des Services sociaux: Programme national de santé publique 2003-2012. [http://www.rrsss12.gouv.qc.ca/documents/ Programme_nationale_sante_pub.pdf].

5. Anderson C, Blenkinsopp A, Armstrong M: The contribution of community pharmacy to improving the public's health: summary report of the litterature review 1990-2007.[http://eprints.nottingham.ac.uk/1576/]

6. Dent LA, Harris KJ, Noonan CW: Randomized trial assessing the effectiveness of a pharmacist-delivered program for smoking cessation. Ann Pharmacother 2009, 43:194-201.

7. Maguire TA, McElnay JC, Drummond A: A randomized controlled trial of a smoking cessation intervention based in community pharmacies. Addiction 2001, 96:325-331.

8. Hersberger KE, Botomino A, Mancini M, Bruppacher R: Sequential screening for diabetes-evaluation of a campaign in Swiss community pharmacies. Pharm World Sci 2006, 28:171-179.

9. Snella KA, Canales AE, Irons BK, Sleeper-Irons RB, Villarreal MC, LeviDerrick VE, Greene RS, Jolly JL, Nelson AA: Pharmacy- and communitybased screenings for diabetes and cardiovascular conditions in high-risk individuals. J Am Pharm Assoc 2006, 46:370-377.

10. Mangum SA, Kraenow KR, Narducci WA: Identifying at-risk patients through community pharmacy-based hypertension and stroke prevention screening projects. J Am Pharm Assoc (Wash) 2003, 43:50-55.

11. Anderson C, Blenkinsopp A: Community pharmacy supply of emergency hormonal contraception: a structured literature review of international evidence. Hum Reprod 2006, 21:272-284.

12. Yuksel N, Majumdar SR, Biggs C, Tsuyuki RT: Community pharmacistinitiated screening program for osteoporosis: randomized controlled trial. Osteoporos Int 2010, 21:391-398.

13. Liu Y, Nevins JC, Carruthers KM, Doucette WR, McDonough RP, Pan X: Osteoporosis risk screening for women in a community pharmacy. J Am Pharm Assoc 2007, 47:521-526.

14. Goode JV, Swiger K, Bluml BM: Regional osteoporosis screening, referral, and monitoring program in community pharmacies: findings from Project ImPACT: osteoporosis. J Am Pharm Assoc 2004, 44:152-160.

15. Hess KM, Dai CW, Garner B, Law AV: Measuring outcomes of a pharmacist-run travel health clinic located in an independent community pharmacy. J Am Pharm Assoc 2010, 50:174-180.

16. Weitzel KW, Goode JV: Implementation of a pharmacy-based immunization program in a supermarket chain. J Am Pharm Assoc (Wash) 2000, 40:252-256.

17. Nkansah N, Mostovetsky O, Yu C, Chheng T, Beney J, Bond CM, Bero L: Effect of outpatient pharmacists' non-dispensing roles on patient outcomes and prescribing patterns. Cochrane Database Syst Rev 2010, 7: CD000336. 
18. United-Kingdom Department of Health: Choosing health through pharmacy-a programme for pharmaceutical public health 2005-2015.

[http://www.dh.gov.uk/en/Publicationsandstatistics/Publications/ PublicationsPolicyAndGuidance/DH_4107494].

19. Phaneuf M: Bill 90 and the therapeutic nursing plan.[http://www. infiressources.ca/fer/Depotdocument_anglais/ Bill_90 and the therapeutic nursing_plan.pdf]

20. Jorgenson $\bar{D}$, Lamb D, MacKinnon NJ: Practice change challenges and priorities: a national survey of practising pharmacists. Can Pharm J 2011, 144:125-131

21. Eades CE, Ferguson JS, O'Carroll RE: Public health in community pharmacy: a systematic review of pharmacist and consumer views. BMC Publ Health 2011, 11:582

22. Anderson C, Blenkinsopp A, Armstrong M: Feedback from community pharmacy users on the contribution of community pharmacy to improving the public's health: a systematic review of the peer reviewed and non-peer reviewed literature 1990-2002. Health Expect 2004, 7:191-202.

23. Canadian Pharmacists Association: Pharmacists and primary health care. [http://www.pharmacists.ca/content/about_cpha/whats_happening/ cpha_in_action/pdf/primaryhealth2a.pdf].

24. Amsler MR, Murray MD, Tierney WM, Brewer N, Harris LE, Marrero DG, Weinberger M: Pharmaceutical care in chain pharmacies: beliefs and attitudes of pharmacists and patients. J Am Pharm Assoc 2001, 41:850-855.

25. René-Henri N, Khamla Y, Nadaira N, Ouellet C, Blais L, Lalonde L, Collin J, Beauchesne MF: Community pharmacists' interventions in asthma care: a descriptive study. Ann Pharmacother 2009, 43:104-111.

26. Krska J, Morecroft CW: Views of the general public on the role of pharmacy in public health. J Pharm Health Serv Res 2010, 1:33-38.

27. Roberts AS, Benrimoj SI, Chen TF, Williams KA, Hopp TR, Aslani P: Understanding practice change in community pharmacy: a qualitative study in Australia. Res Soc Adm Pharm 2005, 1:546-564.

28. Roberts AS, Benrimoj SI, Chen TF, Williams KA, Aslani P: Practice change in community pharmacy: quantification of facilitators. Ann Pharmacother 2008, 42:861-868

29. Dillman DA: Mail and Internet Surveys: the Tailored Design Method New York: John Wiley and Sons Inc:; 2000.

30. Équipe de recherche en soins de première ligne du Centre de santé et de services sociaux de Laval: Questionnaire aux pharmaciens.[http://www. recherchepl.ca/autres-productions-scientifiques.php].

31. Ordre des pharmaciens du Québec: Rapport annuel 2010-2011.[http:// www.opq.org/fr/publications/rapport].

\section{Pre-publication history}

The pre-publication history for this paper can be accessed here: http://www.biomedcentral.com/1471-2458/12/192/prepub

doi:10.1186/1471-2458-12-192

Cite this article as: Laliberté et al: Ideal and actual involvement of community pharmacists in health promotion and prevention: a crosssectional study in Quebec, Canada. BMC Public Health 2012 12:192.

\section{Submit your next manuscript to BioMed Central and take full advantage of:}

- Convenient online submission

- Thorough peer review

- No space constraints or color figure charges

- Immediate publication on acceptance

- Inclusion in PubMed, CAS, Scopus and Google Scholar

- Research which is freely available for redistribution

Submit your manuscript at www.biomedcentral com/submit 